\title{
Perceptions of Powerlessness Are Negatively Associated with Taking Action on Climate Change: A Preregistered Replication
}

Matt N. Williams and Bruce A. Jaftha

School of Psychology, Massey University, Auckland, New Zealand.

\section{Abstract}

Despite segments of skepticism, the majority of the general public in most countries believe that climate change is occurring and caused by human activities. Behavior changes by individuals can reduce greenhouse gas emissions to at least some extent, but a range of psychological and economic barriers can prevent individuals from taking action. A survey of New Zealanders by Aitken, Chapman, and McClure (2011) reported that belief in human influence on climate change and the risks of climate change were positively correlated with taking action on climate change. Conversely, perceptions of powerlessness and the commons dilemma were negatively correlated with taking action on climate change. Feeling powerless was associated with placing less importance on climate change as an influence on actions. Although the study by Aitken et al. has been influential, it was exploratory in nature, had a moderate sample size, was not preregistered, and has not previously been replicated. In this study, we report a preregistered replication with a sample of 352 Australians testing four hypotheses based on Aitken et al.'s findings (as summarized above). All four hypotheses were supported, reproducing Aitken et al.'s key findings. Key Words: Climate change-PowerlessnessCommons dilemma-Behavior change-Ecopsychology-Conservation psychology.

\section{Introduction}

he Earth is warming, and human activities are primarily to blame (IPCC, 2014b). These two claims are the subject of a remarkably strong scientific consensus: Approximately 97\% of actively publishing climate scientists agree with them (Cook et al., 2016). Despite substantial skepticism in some portions of the general public, more than half the population in most countries believes that human activities are to blame for increasing global temperatures (Pelham, 2009). There are a variety of reasons why an individual may not believe that anthropogenic climate change is occurring, but a particularly strong predictor of belief in climate change seems to be political affiliation: A meta-analysis by Hornsey, Harris, Bain, and Fielding (2016) found that supporters of more liberal political parties are more likely to believe that the climate is changing (see also McCright \&t Dunlap, 2011).

Anthropogenic climate change is predicted to have substantial negative impacts on the global environment, including impacts on weather systems, habitats, and both human and nonhuman life on Earth (see IPCC, 2014a). Although effective action on climate change will almost inevitably require coordinated action at a governmental and intergovernmental level, behavior changes by individuals-for example, minimizing aircraft travel, reducing meat consumption, and limiting the use of private automobiles-do have some capacity to reduce greenhouse gas emissions (Wynes \& Nicholas, 2017).

However, even when an individual believes that climate change is a problem and is aware of strategies they could use to reduce greenhouse gas emissions, there exist a range of barriers that may prevent them from taking action. Gifford (2011) notes that while 


\section{WILLIAMS AND JAFTHA}

there obviously exist structural barriers to action on climate change (e.g., one cannot use public transport if one lives in an area where public transport is not available), there also exist important psychological barriers to action. Some of the barriers highlighted by Gifford include judgmental discounting (i.e., the tendency to undervalue distant and future risks), behavioral momentum (i.e., habits), perceived risks associated with behavioral change, and tokenism (i.e., a predilection to engage in low-cost behavior that is nominally proenvironmental but has little real effect). This said, there exists uncertainty with respect to both the effects of various barriers to climate action and the possibility of variation in their effects. For example, summarizing prior literature, Hendrickx and Nicolaij (2004) note that a substantial percentage of individuals do not seem to apply temporal/judgmental discounting to future environmental risks.

One particularly important barrier to action on climate change is the fact that climate change has the incentive structure of a tragedy of the commons-a term coined by the ecologist Garrett Hardin (1968) to describe a situation originally described by the economist William Forster Lloyd (1833). A tragedy of the commons (or "commons dilemma") occurs within a community that shares resources when the benefit from a particular action accrues to the individual taking that action, whereas the cost of the action is not solely borne by the individual but rather shared with the community. This combination of incentives can result in rational individuals taking actions whose net benefit is positive for the individual but negative for the community. This incentive structure applies in the context of climate change. Decision-makers such as individual people, corporations, and other organizations benefit directly from actions that cause greenhouse gas emissions (driving cars, utilizing airplane travel, mining fossil fuels, purchasing imported goods, etc.). However, the environmental costs of an action resulting in greenhouse gas emissions are not borne solely by the individual or organization taking that action but rather shared across life on the planet as whole (including nonhuman species and even future generations; see Gardiner, 2006).

At an individual level, people may feel powerless to combat climate change and believe that taking action will have little effect unless others take collective and consistent action. Yet some individuals clearly do take action on climate change-a phenomenon studied in the literature on climate activism (e.g., Cassegård \& Thörn, 2018; Kleres \& Wettergren, 2017; Roser-Renouf, Maibach, Leiserowitz, \& Zhao, 2014). It is important to investigate, then, what causes some to take action in relation to climate change while others do not, and which barriers inhibit individual action.

In an important example of research on this topic, a study by Aitken, Chapman, and McClure (2011) examined a range of barriers to climate change action in a survey of 192 adult New Zealanders recruited in public spaces. Included among the barriers examined were powerlessness and perceptions of the "commons dilemma" (an alternative term for a tragedy of the commons). Aitken et al. examined how perceptions of these barriers related to participants' selfreports about whether they had taken action on climate change. Taking action on climate change was operationalized as the response to the item "Have you changed your actions, at least partly, due to consideration of climate change?" (yes or no).

One of Aitken et al.'s principal findings was that participants were less likely to report taking action on climate change if they endorsed statements indicating that feelings of powerlessness influenced their decisions about actions relating to climate change, $r=.20, p<.01$. Likewise, participants who reported stronger perceptions of the commons dilemma (i.e., who indicated that concerns such as "Feeling that other individuals will not change their actions even if I do" had been influential over their decisions relating to climate change) were less likely to report taking action on climate change, $r=.27, p<.001$.

In addition to investigating the barriers to action discussed above, Aitken et al. also estimated the degree to which perceived human influence on climate change and perceived risk of climate change predicted taking action on climate change. Aitken et al. initially created perceived human influence and perceived risk of climate change as separate variables but ultimately combined them into a composite variable. They did this because when the variables were entered separately in a regression analysis "each variable greatly reduced the predictive power and significance of the other" (2011, p. 756). When entered in a regression model along with 10 other psychological and demographic predictor variables (the same 10 variables shown in Table 4 for our own study below), the composite variable of perceived human influence and perceived risk of climate change had a strong relationship with taking action on climate change, standardized $\beta=.40, p<.001$.

In the years since the study by Aitken et al. (2011) was published, there has been increasing awareness of problems with the replicability of findings in psychology and other disciplines-a phenomenon sometimes referred to as the replication crisis (see Tackett, Brandes, King, \& Markon, 2019). For example, an attempt to replicate 100 published studies in psychology was only able to successfully reproduce the findings of around a third of those studies (Open Science Collaboration, 2015). These problems imply that it is wise to treat the findings of almost any individual psychological study as tentative until it has been independently replicated. Problems with replicability are particularly concerning in the context of psychological research about high-stakes issues such as climate change (Williams $\mathrm{Ct}$ 


\section{TAKING ACTION ON CLIMATE CHANGE}

Bond, 2020). Furthermore, enhancing the transparency and replicability of psychological research about climate change is important in light of the significant skepticism about climate change research that is present among some members of the general public (see for example Lewandowsky et al., 2015).

In addition, there are specific reasons why the study by Aitken et al. (2011) is particularly important to replicate. Their study has been relatively influential in the academic literature, accruing well over 100 citations, but has not previously (to our knowledge) been subject to a close replication. It also did not involve a preregistered analysis plan (see Nosek, Ebersole, DeHaven, \&t Mellor, 2018). Finally, the original study included at least one inappropriate data analysis decision: Whether or not participants reported taking action on climate change (a binary variable) was treated as a continuous outcome variable in their regression model, and this same regression model included multicategory nominal predictors (age bracket, income bracket) which were apparently treated as if they were quantitative rather than converted into sets of dummy variables.

Therefore, in this study, we aimed to replicate the work of Aitken et al. (2011). Our replication is best characterized as close rather than exact (see Brandt et al., 2014): We used the same design and materials but a slightly different population (Australians rather than New Zealanders), and data was collected online rather than in person. The choice to sample Australians was guided both by a practical consideration (the larger population of Australia makes it more feasible to quickly recruit a large sample of participants) and the desire to determine whether the findings replicated in a slightly different population. Australia and New Zealand are geographically proximal countries with substantial linguistic and cultural similarities but do have some relevant differences. For example, while New Zealand does produce substantial greenhouse gas emissions relative to its population (16.9 tonnes $\mathrm{CO}_{2}$-equivalent per capita in 2016; $\mathrm{NZ}$ Ministry for the Environment, 2019), Australia's emissions are even greater (22.2 tonnes per capita in 2016; Department of Agriculture, Water and the Environment, 2019). This is partly due to the fact that Australia is one of the largest producers of coal in the world (see U.S. Energy Information Administration, n.d.). Such differences between Australia and New Zealand may mean that residents of these two countries may differ in how they respond to questions about climate change such as those posed in Aitken et al.'s study.

In any replication study, it is necessary to determine which findings in the original study are the most important targets for reproduction. Aitken et al.'s empirical findings consisted primarily of a correlation matrix of 11 variables relating to beliefs and actions in relation to climate change (including endorsement of various psy- chological barriers to action), and two regression models, each with 11 predictors. The first of these regression models had whether a participant reported taking action on climate change as the outcome variable, and the second model had the importance the individual placed on climate change in influencing their actions as the outcome variable. This implies that there were thus a relatively large number of statistical estimates that could be considered targets for replication, and no explicit list of hypotheses to indicate which of these estimates was the most important. As such, we decided to focus our replication on those empirical claims which were included in Aitken et al.'s abstract, which provides an indication of what could be considered the key conclusions of their study.* Our hypotheses were as follows:

(1) Stronger perceptions of powerlessness are related to lower levels of action to mitigate climate change.

(2) Stronger perceptions of the commons dilemma are related to lower levels of action to mitigate climate change.

(3) Stronger perceptions of powerlessness are related to lesser importance being placed on climate change as an influence on individual actions.

(4) A composite variable composed of the perceived risk of climate change and the perceived human influence on climate change has a positive relationship with taking action on climate change when controlling for the effects of the following variables: perceptions of the commons dilemma, income, option difficulty, confusion, age, gender, how informed, qualification level, powerlessness, and looking foolish.

Our hypotheses and plans for data collection and analysis were preregistered prior to data collection. ${ }^{\dagger}$

A note on terminology: In parts of our preregistration (e.g., H1 and $\mathrm{H} 2$ above), we used the term "action to mitigate climate change" to refer to our main dependent variable. This follows the terminology

*We excluded the claim in Aitken et al.'s abstract that "Stronger perceptions of $[. .$.$] the commons dilemma were related to [...] lesser importance being$ placed upon climate change as an influence on individual actions" (p. 752). This claim appears to have been made in error: Their Table 2 indicated that there was no significant correlation between the degree to which participants reported climate change as being an influence on their individual actions and perceptions of the commons dilemma, $r=.02, p>.05$. Similarly, their Table 5 indicates that perceptions of the commons dilemma was not a significant predictor of importance placed upon climate change as an influence on individual actions.

${ }^{\dagger}$ For the preregistration, along with the deidentified data and our analysis code, see https://osf.io/3j8xn 


\section{WILLIAMS AND JAFTHA}

used in Aitken et al.'s abstract. In this article, we use the more general descriptor "action on climate change" (also used in Aitken et al.), since the relevant item in the survey itself does not distinguish between actions to mitigate climate change and actions to adapt to climate change.

\section{Materials and Methods}

Participants and procedures

This study used a cross-sectional survey design with a convenience sample. Participants were recruited via Prolific Academic and completed a survey constructed using Qualtrics. Participants were paid GBP1 each (at the time, equating to approximately AUD1.83; Prolific Academic is located in the United Kingdom, hence the denomination of payments in pounds). Our inclusion criteria were as follows:

- Participants had to be aged 18 or over (only individuals over the age of 18 can sign up for Prolific Academic);

- Participants had to be residents of Australia (this was specified as a prescreening criterion on Prolific Academic).

A target sample size of 350 participants was specified in Prolific Academic. This target was determined according to a combination of resource constraints and the desire to substantially exceed the sample size in the original study $(N=192)$. Slightly more participants (353) submitted responses than the target sample size.

Our preregistration specified that we would exclude participants who did not provide any data on any one of the key study variables (questions 3, 4, 7-12, 14-19) t $^{*}$ and participants taking the survey multiple times (as indicated by a matching IP address, in which case their second and subsequent responses would be excluded). These criteria resulted in the exclusion of just a single row of data (a person who completed the survey once, then opened the survey a second time, and then stopped responding). Our final sample size was thus $N=352$. A sensitivity power analysis conducted after data collection suggested that the final sample size delivered 80\% power to detect correlations of absolute value 0.15 or greater (Hypotheses 1 to 3), and to detect an effect size $f^{2}$ greater than 0.022 for a single coefficient in a multiple regression model with 11 predictors (Hypothesis 4). As such, the study delivered adequate power to detect even relatively small effects.

Within the final sample, the only cases of completely missing responses were two participants who left the gender item blank (and who were thus excluded from analyses treating gender as a predictor). Three participants who identified themselves as gender diverse

\footnotetext{
"See our questionnaire at https://osf.io/3j8xn
}

were retained in the sample but were excluded from analyses that used gender as a predictor (as preregistered). The gender and income items also had an explicit "prefer not to say" response option, which was not selected by any participants for gender but was selected by 24 participants for income. These 24 participants were included in the sample but excluded from those analyses including income as a predictor (Hypothesis 4). See Supplementary Table S1 for more discussion of these decisions relating to gender and income, which represented minor deviations from our preregistration.

Within our final sample, the modal age bracket was 20-29 (51\%); $52 \%$ of participants were male, $47 \%$ female, and 1\% gender diverse; $59 \%$ had a tertiary qualification (tertiary degree or other); and the modal income bracket was \$0-\$25,000 p.a. (37\%).

The study was evaluated via peer review and determined to be low risk according to the criteria set by the Massey University Human Ethics Committees. A low-risk notification was lodged with Massey University.

\section{Measures}

The questionnaire items were those used in the study by Aitken et al. The questionnaire had three sections. The first section comprised questions about participants' knowledge of and opinion about climate change. This included the key dependent variable in our study, whether the participant reported taking action on climate change: "Have you changed your actions, at least partly, due to consideration of climate change?" (yes or no). The second section comprised questions about which factors had been influential in shaping participants' decisions about actions in relation to climate change. The third section asked participants for some basic demographic information: age (1819, 20-29, 30-39, 40-49, 50-59, 60+), gender (male, female, gender diverse, prefer not to say), education level (no qualification, high school qualification, tertiary degree, tertiary other), and individual income (\$0$\$ 25,000, \$ 25,001-\$ 50,000, \$ 50,001-\$ 75,000, \$ 75,001+$, prefer not to say). Our format for these demographic items closely approximated that in Aitken et al.'s study, albeit with minor changes (e.g., an addition of a "gender diverse" option; the addition of "prefer not to say" options for the gender and income items). The main items are displayed in Table $1 .{ }^{\S}$

A subset of the measured variables were indices/composites made up of responses to multiple items; our creation of these indices mirrors the approach in Aitken et al., and the planned indices were recorded in our preregistration. The internal consistency reliability of each of these indices was estimated using Cronbach's alpha. Internal

${ }^{\S}$ For the full study questionnaire, see https://osf.io/3j8xn 
TAKING ACTION ON CLIMATE CHANGE

Table 1. Descriptive Statistics for Survey Items

ITEM

01 How well informed do you consider yourself on the issue of climate change? (1 - Not informed; 5 - Very well informed)

Q2 To what extent do you believe human activity is contributing to climate change? ( 1 - Not at all; 5 - A lot)

Q3 How severe do you consider the problem of climate change? (1 - Not a problem; 5 - A huge problem)

Q4 How soon should climate change be dealt with? (1 - Never; 5 - Immediately)

Q5 Have you changed your actions, at least partly, due to consideration of climate change? (Yes / No)

06 How much has climate change been a factor in changing your actions? (1 - A minor factor; 5 - A major factor)

How influential have the following factors been in shaping your own decisions about actions that might affect climate change? (Anchors: 1 - not influential to 5 - Very influential)

07 The monetary cost of changing my actions

Q8 The availability of options for change

Q9 The inconvenience of options for change

010 Fitting changes in with family and others

011 Lack of knowledge about possible changes I can make

Q12 Uncertainty about the best option to contribute to reducing climate change

Q13 Uncertainty as to whether climate change is a significant problem

Q14 The feeling that climate change is too big for my actions to have an impact

Q15 The feeling that my actions will not affect the outcome of climate change

016 The feeling that my contribution is just a drop in the ocean and so is insignificant

Q17 Feeling that other individuals will not change their actions even if I do

Q18 Unfairness associated with bearing the cost of change whilst others do not

Q19 Other countries or people not taking equivalent action currently

Q20 Looking foolish due to being the only one to change actions

\begin{tabular}{|c|c|}
\hline$M$ & $S D$ \\
\hline 3.34 & 0.99 \\
\hline 4.43 & 0.80 \\
\hline 4.65 & 0.61 \\
\hline 4.65 & 0.71 \\
\hline 0.81 & 0.39 \\
\hline 3.47 & 0.92 \\
\hline & \\
\hline 3.41 & 1.13 \\
\hline 3.70 & 0.97 \\
\hline 3.15 & 1.10 \\
\hline 2.72 & 1.24 \\
\hline 3.09 & 1.19 \\
\hline 3.14 & 1.20 \\
\hline 1.58 & 1.01 \\
\hline 2.67 & 1.34 \\
\hline 2.67 & 1.31 \\
\hline 2.78 & 1.35 \\
\hline 2.62 & 1.39 \\
\hline 2.43 & 1.31 \\
\hline 2.62 & 1.48 \\
\hline 1.69 & 1.11 \\
\hline
\end{tabular}

Items are reproduced from Aitken et al. (2011, p. 755), @Elsevier Inc. Reprinted with permission.

consistency was high for the measures of powerlessness $(\alpha=.94)$ and perceptions of the commons dilemma $(\alpha=.82)$, moderate for perceived risk and human influence $(\alpha=.79)$ and option uncertainty $(\alpha=.73)$, but lower for option difficulty $(\alpha=.62)$.

\section{Results}

Descriptive statistics

Descriptive statistics for the responses to survey items (except demographic variables) are displayed in Table 1, and descriptive statistics for the indices/composite variables are displayed in Table 2. A majority (81\%) of participants reported that they had taken action on climate change. Participants generally seemed to believe that human activity is substantially affecting the climate; 59\% of participants indicated that they believed that human activity is contributing "A lot" to climate change, and just one person believed that it is not contributing to climate change at all.

Two items with particularly high means were Q3 ("How severe do you consider the problem of climate change") and Q4 ("How soon 
WILLIAMS AND JAFTHA

\begin{tabular}{|c|c|c|c|c|}
\hline VARIABLE & ITEMS & POSSIBLE RANGE & M & $S D$ \\
\hline Perceived risk and human influence & $02-4$ & $3-15$ & 13.73 & 1.79 \\
\hline Option difficulty & $07-10$ & $4-20$ & 12.98 & 3.04 \\
\hline Option uncertainty & 011-12 & $2-10$ & 6.23 & 2.11 \\
\hline Powerlessness & 014-16 & $3-15$ & 8.11 & 3.79 \\
\hline Perceptions of the commons dilemma & 017-19 & $3-15$ & 7.67 & 3.59 \\
\hline
\end{tabular}

should climate change be dealt with?"). The mean for Q3 was 4.65 out of 5 , with $70 \%$ of participants rating climate change as a "huge" problem (the right-most option on the response scale). The mean for Q4 was also 4.65 out of 5, with 75\% of participants suggesting that climate change should be dealt with "immediately." The means for these two items were somewhat higher than their respective estimates in Aitken et al.'s study (3.83 for Q3, 4.25 for Q4).

\section{Bivariate relationships (Hypotheses 1-3)}

Table 3 displays Pearson's product-moment correlation coefficients estimating the relationships between the main variables in this study, replicating Aitken et al.'s Table 3. There was a significant negative correlation of medium size between perceptions of powerlessness and taking action on climate change, $r(350)=-.38, p<.001,95 \%$ CI $[-.47,-.29]$, supporting Hypothesis 1 . There was also a moderate negative correlation between perceptions of the commons dilemma and taking action on

\begin{tabular}{|c|c|c|c|c|c|c|c|c|c|c|c|}
\hline NO. & VARIABLE & 1 & 2 & 3 & 4 & 5 & 6 & 7 & 8 & 9 & 10 \\
\hline 1 & How informed (01) & $1.00^{*}$ & & & & & & & & & \\
\hline 2 & Perceived risk \& human influence ${ }^{a}$ & $.32^{*}$ & 1.00 & & & & & & & & \\
\hline 3 & Taking action on climate change (02) & $.26^{*}$ & $.52^{*}$ & 1.00 & & & & & & & \\
\hline 4 & Importance placed on climate change as an influence on actions $(06)^{b}$ & $.39^{*}$ & $.39^{*}$ & b & 1.00 & & & & & & \\
\hline 5 & Option difficulty & $.12^{*}$ & $.11^{*}$ & .04 & .08 & 1.00 & & & & & \\
\hline 6 & Option uncertainty & $-.26^{*}$ & .08 & -.04 & $-.18^{*}$ & $.23^{*}$ & 1.00 & & & & \\
\hline 7 & Uncertainty as to whether climate change is a significant problem (013) & $-.24^{*}$ & $-.43^{*}$ & $-.25^{*}$ & $-.17^{*}$ & .06 & .04 & 1.00 & & & \\
\hline 8 & Powerlessness & $-.14^{*}$ & $-.23^{*}$ & $-.38^{*}$ & $-.21^{*}$ & $.19^{*}$ & $.21^{*}$ & $.29^{*}$ & 1.00 & & \\
\hline 9 & Perceptions of the commons dilemma & -.04 & $-.20^{*}$ & $-.24^{*}$ & $-.15^{*}$ & $.23^{*}$ & $.18^{*}$ & $.32^{*}$ & $.59^{*}$ & 1.00 & \\
\hline 10 & Looking foolish (020) & -.02 & $-.11^{*}$ & -.09 & -.05 & $.19^{*}$ & $.15^{*}$ & $.30^{*}$ & $.26^{*}$ & $.47^{*}$ & 1.00 \\
\hline \multicolumn{12}{|c|}{$\begin{array}{l}{ }^{a} \text { Aitken et al.'s Table } 2 \text { included perceived risk of climate change and human influence on climate change as separate variables. They are combined here for consistency with } \\
\text { the regression analyses and preregistered hypothesis tests. }\end{array}$} \\
\hline \multicolumn{12}{|c|}{$\begin{array}{l}\text { bThe item measuring importance placed on climate change as an influence on actions ( } 06) \text { was only presented to participants who responded yes to the question asking } \\
\text { whether they had taken action on climate change (02). Correlations including this variable thus have a sample size of } 285 \text { ( } N=352 \text { for other correlations), and the } \\
\text { correlation between this variable and whether or not the person took action on climate change is not calculable. }\end{array}$} \\
\hline \multicolumn{12}{|c|}{ Composite variables are displayed in italics. } \\
\hline
\end{tabular}


TAKING ACTION ON CLIMATE CHANGE

\begin{tabular}{|c|c|c|c|c|}
\hline & $b$ & LL & UL & $\beta$ \\
\hline Intercept & $-0.425^{*}$ & -0.797 & -0.052 & \\
\hline Q1 How Informed & 0.040 & -0.001 & 0.080 & 0.101 \\
\hline Option uncertainty (confusion) & 0.000 & -0.019 & 0.018 & -0.002 \\
\hline Powerlessness & $-0.029^{*}$ & -0.040 & -0.017 & -0.282 \\
\hline Perceptions of the commons dilemma & 0.000 & -0.014 & 0.013 & -0.004 \\
\hline Education & 0.032 & -0.028 & 0.092 & 0.052 \\
\hline Income & 0.001 & -0.032 & 0.035 & 0.004 \\
\hline
\end{tabular}

$b=$ unstandardized regression coefficient. $\beta=$ standardized regression coefficient.

"Three participants with gender $=$ "gender diverse" are excluded from this analysis.

The bold emphasizes the main predictor variable of interest (as per Hypothesis 4).

${ }^{*} p<.05$.

climate change, $r(350)=-.24, p<.001,95 \%$ CI [-.34, -.14], supporting Hypothesis 2 . The correlation between perceptions of powerlessness and the importance placed on climate change as an influence on actions (Q6) was slightly weaker but also significant, $r(283)=-.21, p<.001,95 \%$ CI [.32, -.09], supporting Hypothesis 3 . While not the subject of a hypothesis, an exploratory analysis indicated there was a strong correlation between perceived risk and human influence of climate change and taking action on climate change, $r(350)=.52, p<.001,95 \% \mathrm{CI}[.44, .59]$.

\section{Regression analyses (Hypothesis 4)}

Replicating Aitken et al.'s approach, we estimated a multiple regression model using ordinary least squares (OLS) to determine whether perceived risk and human influence on climate change (composite variable of questions $2,3,4)^{* *}$ had a positive relationship with taking action

**Our preregistration erroneously excluded item 2 from the list of items making up the risk and human influence variable. See Supplementary Table S2 for the results given the original preregistered specification with item 2 excluded. on climate change when controlling for perceptions of the commons dilemma, income, option difficulty, confusion, age, gender, how informed, qualification level, powerlessness, and looking foolish. The results of this analysis are presented in Table 4. The regression coefficient for perceived risk and human influence was positive and statistically significant, $\beta=0.402, p<.001$, supporting Hypothesis 4 .

Although the analysis above supports $\mathrm{H} 4$, it duplicates Aitken et al.'s approach of using an OLS regression model where all predictor variables and the outcome variable are treated as quantitative-even though the outcome variable (taking action on climate change) is dichotomous, and some of the predictors are categorical. The application of OLS to estimate a regression model with a dichotomous outcome variable is often referred to as the "linear probability model," and it has well-known problems (e.g., the inevitable presence of heteroscedasticity and therefore inefficient estimates; see Liao, 1994).

We therefore preregistered a plan to complete a robustness analysis for $\mathrm{H} 4$ in which the outcome and predictor variables were the 
same as above, but with income and age treated as categorical predictors and taking action on climate change as a dichotomous outcome variable. Subsequent to data collection, we realized that education level should also be treated as categorical; the analysis we report here includes it as such and therefore represents a minor deviation from the preregistration (see the Supplementary Data for a more detailed rationale, and Supplementary Table S3 for results based on the original preregistered specification). Hypothesis 4 was supported in this robustness check: The coefficient for perceived risk and human influence was positively and statistically significant at the .05 alpha level, $\exp (b)=1.92, p<.001$. See Table 5 for the coefficients for all variables in this model. See Supplementary Table S4 for an additional regression model with the importance placed on climate change as an influence on actions as the outcome variable (replicating Aitken et al.'s Table 4).

\section{Discussion}

On the basis of Aitken et al.'s results, we hypothesized that perceptions of powerlessness (H1) and the commons dilemma (H2) would be related to a lower probability of taking action on climate change. While at a holistic level climate change may be considered as a tragedy of the commons and a problem that individuals have little power to address, individuals vary in the extent to which they feel powerless in relation to climate change and in the extent to which they report being influenced by the concern that others are not taking action (i.e., perceptions of the commons dilemma/tragedy of the commons). Perceptions of powerlessness and the commons dilemma do seem to be related to whether participants report taking action on climate change; in our replication, $\mathrm{H} 1$ and $\mathrm{H} 2$ were supported. In addition, perceptions of powerlessness and perceptions of the commons dilemma were themselves quite strongly correlated with one another $(r=.59)$, much as they were in Aitken et al.'s study $(r=.62)$. H3 (that perceptions of powerlessness are related to less importance being placed on climate change as an influence on actions) was also supported.

Furthermore, we hypothesized that perceived risks and human influence on climate change would have a positive relationship with taking action on climate change (H4). This hypothesis was supported both when tested via an OLS regression model (replicating Aitken et al.'s approach) and also when tested via a more appropriate binary logistic regression model. In both of these regression models, perceptions of powerlessness was a significant (negative) predictor of taking action on climate change, while perceptions of the commons dilemma was not. This suggests that-while H2 is supported-the apparent negative bivariate relationship between perceptions of the
Table 5. Binary Logistic Regression with Taking Action on Climate Change as Outcome Variable

\begin{tabular}{|c|c|c|c|c|}
\hline & & & $95 \% \mathrm{C}$ & or $\operatorname{Exp}(b)$ \\
\hline & $\boldsymbol{b}$ & $\operatorname{Exp}(b)$ & LL & UL \\
\hline Intercept & $-6.038^{*}$ & 0.002 & 0.000 & 0.115 \\
\hline Q1 How Informed & $0.535^{*}$ & 1.707 & 1.087 & 2.753 \\
\hline $\begin{array}{l}\text { Perceived risk and human } \\
\text { influence }\end{array}$ & $0.651^{*}$ & 1.918 & 1.519 & 2.504 \\
\hline Option difficulty & 0.044 & 1.045 & 0.914 & 1.197 \\
\hline Option uncertainty (confusion) & -0.103 & 0.902 & 0.722 & 1.116 \\
\hline Powerlessness & $-0.373^{*}$ & 0.689 & 0.582 & 0.798 \\
\hline $\begin{array}{l}\text { Perceptions of the commons } \\
\text { dilemma }\end{array}$ & -0.012 & 0.988 & 0.855 & 1.141 \\
\hline Q20 Looking foolish & 0.042 & 1.043 & 0.724 & 1.530 \\
\hline Age $^{\mathrm{a}} 20-29$ & -0.338 & 0.713 & 0.173 & 2.676 \\
\hline Age $30-39$ & -0.131 & 0.877 & 0.182 & 4.044 \\
\hline Age $40-49$ & 0.304 & 1.355 & 0.183 & 11.222 \\
\hline Age $50-59$ & $-2.412^{*}$ & 0.090 & 0.008 & 0.845 \\
\hline Age $60+$ & -0.545 & 0.580 & 0.021 & 16.902 \\
\hline Gender (female $=1^{b}$ ) & 0.364 & 1.438 & 0.641 & 3.272 \\
\hline Education': High School & 0.665 & 1.945 & 0.102 & 35.681 \\
\hline Education: Tertiary degree & 1.155 & 3.175 & 0.165 & 59.685 \\
\hline Education: Tertiary other & 1.439 & 4.216 & 0.170 & 103.944 \\
\hline Income ${ }^{d}: \$ 25,001-\$ 50,000$ & 0.731 & 2.078 & 0.717 & 6.394 \\
\hline Income: $\$ 50,001-\$ 75,000$ & 0.207 & 1.230 & 0.415 & 3.797 \\
\hline Income: $\$ 75,001+$ & 0.049 & 1.050 & 0.304 & 3.758 \\
\hline
\end{tabular}

${ }^{a}$ Reference category: Age $=18-19$

"Three participants with gender $=$ "gender diverse" are excluded from this analysis. ${ }^{c}$ Reference category: No high school qualification.

${ }^{\mathrm{d}}$ Reference category: 0-\$25,000 p.a.

The bold emphasizes the main predictor variable of interest (as per Hypothesis 4). ${ }^{*} p<.05$. 


\section{TAKING ACTION ON CLIMATE CHANGE}

commons dilemma and taking action on climate change could possibly be due to a confounding effect of one or more of the other predictors in the regression model. Alternatively, perceptions of the commons dilemma might have an effect on taking action that is mediated by one or more of the other predictors in the model.

Importantly, the perceptions that climate change is caused by human influence and poses a significant risk were more strongly related to the odds of taking action on climate change than were powerlessness or perceptions of the commons dilemma. Taken at face value, these results suggest that members of the public who know more about the causes and consequences of climate change are more likely to take action to address it. This implies that effective scientific communication about climate change could reduce engagement in behaviors that result in greenhouse gas emissions. That said, this inference comes with important caveats. First, while it is plausibly the case that communication with the public can increase belief in the reality and risks of climate change (e.g., Kerr \& Wilson, 2018), it is less obviously the case that beliefs about climate change necessarily translate into action, or useful action (see Whitmarsh, 2009). More broadly, our correlational design obviously does not produce a basis for confident causal inferences.

\section{Limitations and future directions}

As a replication, our study had some small differences from the original: We drew participants from a different country (Australia rather than New Zealand), and we used online rather than in-person data collection. While our study was preregistered, some minor deviations from the preregistration transpired to be necessary during data processing and analysis (see the Supplementary Data). Our preregistered analyses also relied on significance tests for determining whether particular findings were supported/replicated, rather than quantitatively testing whether our estimates of relationships were consistent with those in the original study (see for example the Bayesian methods discussed in Verhagen \&t Wagenmakers, 2014).

Other more general limitations are shared by both our replication study and the original. These include the convenience sample, the cross-sectional correlational design, and the reliance on self-reported data. Most of these limitations are admittedly difficult to address in research focused on the psychological predictors of action on climate change due to resource and ethical constraints. However, one specific feasible improvement that could be made in future studies in this area would be to use sequences of specific targeted questions to estimate participants' carbon footprints (e.g., Rahman, O'Brien, Ahamed, Zhang, \&t Liu, 2011), rather than relying on participants' subjective determinations of whether or not they have taken action in consideration of climate change. Such measurements could produce a stronger basis for inferences about the degree to which psychological variables predict the extent to which individuals engage in behavior contributing to climate change. In the current study-as was the case in Aitken et al.'s study-we asked participants only whether they had changed their actions (even partly) in consideration of climate change, and did not probe them for information about which specific actions they had actually taken. It is entirely possible that some participants may have taken actions they believe to be helpful but that are actually ineffective or even counterproductive in addressing climate change (e.g., using disposable paper bags rather than plastic ones; see Edwards \&t Meyhoff Fry, 2011).

Finally, we urge researchers in conservation psychology and ecopsychology to conduct and report replication studies and to ensure that their published studies are described in sufficient detail to be replicable (see Asendorpf et al., 2013; Spellman, 2015). The provision of exact question wording by Aitken et al. (2011) facilitated replicability in this case, but not all published studies are necessarily described in sufficient detail to be replicable. When research addresses high-stakes issues such as climate change, it is crucial that it is conducted in a fashion that is transparent and replicable.

\section{Author Disclosure Statement}

No competing financial interests exist.

\section{Funding Information}

This study was supported by funding from the Massey University School of Psychology Postgraduate Research Fund.

\section{Supplementary Material}

Supplementary Data

Supplementary Table S1

Supplementary Table S2

Supplementary Table S3

Supplementary Table S4

\section{REFERENCES}

Aitken, C., Chapman, R., \& McClure, J. (2011). Climate change, powerlessness and the commons dilemma: Assessing New Zealanders' preparedness to act. Global Environmental Change, 21, 752-760.

Asendorpf, J. B., Conner, M., Fruyt, F. D., Houwer, J. D., Denissen, J. J. A., Fiedler, K., ... Wicherts, J. M. (2013). Recommendations for increasing replicability in psychology. European Journal of Personality, 27, 108-119.

Brandt, M. J., IJzerman, H., Dijksterhuis, A., Farach, F. J., Geller, J., Giner-Sorolla, R. ... van 't Veer, A. (2014). The replication recipe: What makes for a convincing replication? Journal of Experimental Social Psychology, 50, 217-224. 


\section{WILLIAMS AND JAFTHA}

Cassegård, C., \&t Thörn, H. (2018). Toward a postapocalyptic environmentalism? Responses to loss and visions of the future in climate activism. Environment and Planning E: Nature and Space, 1, 561-578.

Cook, J., Oreskes, N., Doran, P. T., Anderegg, W. R. L., Verheggen, B., Maibach, E. W., ... Rice, K. (2016). Consensus on consensus: A synthesis of consensus estimates on human-caused global warming. Environmental Research Letters, 11, doi:10.1088/1748-9326/11/4/048002

Department of Agriculture, Water and the Environment. (2019). Quarterly update of Australia's national greenhouse gas inventory for March 2019. Parkes, Australia: Department of Agriculture, Water and the Environment. Retrieved from https://publications.industry.gov.au/publications/climate-change/climatechange/climate-science-data/greenhouse-gas-measurement/publications/ quarterly-update-australias-nggi-mar-2019.html

Edwards, C., \& Meyhoff Fry, J. (2011). Life cycle assessment of supermarket carrierbags: A review of the bags available in 2006 (No. SC030148). London, UK: Environment Agency. Retrieved from https://www.gov.uk/government/ publications/life-cycle-assessment-of-supermarket-carrierbags-a-review-ofthe-bags-available-in-2006

Gardiner, S. M. (2006). A perfect moral storm: Climate change, intergenerational ethics and the problem of moral corruption. Environmental Values, 15, 397-413.

Gifford, R. (2011). The dragons of inaction: Psychological barriers that limit climate change mitigation and adaptation. American Psychologist, 66, 290-302.

Hardin, G. (1968). The tragedy of the commons. Science, 162, 1243-1248.

Hendrickx, L. \& Nicolaij, S. (2004). Temporal discounting and environmental risks: The role of ethical and loss-related concerns. Journal of Environmental Psychology, 24, 409-422.

Hornsey, M. J., Harris, E. A., Bain, P. G., \&t Fielding, K. S. (2016). Meta-analyses of the determinants and outcomes of belief in climate change. Nature Climate Change, 6, 622-626.

IPCC. (2014a). Climate change 2014: Impacts, adaptation, and vulnerability. Contribution of Working Group II [WGII] to the Fifth Assessment Report of the Intergovernmental Panel on Climate Change. Cambridge, UK: Cambridge University Press.

IPCC. (2014b). Climate change 2014: Synthesis report. Contribution of Working Groups I, II and III to the Fifth Assessment Report of the Intergovernmental Panel on Climate Change. Geneva, Switzerland: IPCC.

Kerr, J. R., \&t Wilson, M. S. (2018). Changes in perceived scientific consensus shift beliefs about climate change and GM food safety. PLoS One, 13, doi:10.1371/ journal.pone.0200295

Kleres, J., \&t Wettergren, $\AA$. (2017). Fear, hope, anger, and guilt in climate activism. Social Movement Studies, 16, 507-519.

Lewandowsky, S., Cook, J., Oberauer, K., Brophy, S., Lloyd, E. A., \& Marriott, M. (2015). Recurrent fury: Conspiratorial discourse in the blogosphere triggered by research on the role of conspiracist ideation in climate denial. Journal of Social and Political Psychology, 3, 142-178.

Liao, T. F. (1994). Interpreting probability models: Logit, probit, and other generalized linear models. Thousand Oaks, CA: Sage.

Lloyd, W. F. (1833). Two lectures on the checks to population. Retrieved from https://en.wikisource.org/wiki/Two_Lectures_on_the_Checks_to_Population

McCright, A. M., \&t Dunlap, R. E. (2011). Cool dudes: The denial of climate change among conservative White males in the United States. Global Environmental Change, 21, 1163-1172.

Nosek, B. A., Ebersole, C. R., DeHaven, A. C., \& Mellor, D. T. (2018). The preregistration revolution. Proceedings of the National Academy of Sciences, 115, 2600-2606.
NZ Ministry for the Environment. (2019). New Zealand's greenhouse gas inventory 1990-2017. Wellington, New Zealand: Ministry for the Environment, Manatu Mo Te Taiao. Retrieved from https://www.mfe.govt.nz/sites/default/files/media/ Climate\%20Change/snapshot-nzs-greenhouse-gas-inventory-1990-2017.pdf

Open Science Collaboration. (2015). Estimating the reproducibility of psychological science. Science, 349, doi:10.1126/science.aac4716

Pelham, B. (2009, April 22). Awareness, opinions about global warming vary worldwide. Gallup. Retrieved from https://news.gallup.com/poll/117772/Awareness-OpinionsGlobal-Warming-Vary-Worldwide.aspx

Rahman, F., O'Brien, C., Ahamed, S. I., Zhang, H., \& Liu, L. (2011). Design and implementation of an open framework for ubiquitous carbon footprint calculator applications. Sustainable Computing: Informatics and Systems, 1, 257-274.

Roser-Renouf, C., Maibach, E. W., Leiserowitz, A., \& Zhao, X. (2014). The genesis of climate change activism: From key beliefs to political action. Climatic Change, $125,163-178$.

Spellman, B. A. (2015). A short (personal) future history of revolution 2.0. Perspectives on Psychological Science, 10, 886-899.

Tackett, J. L., Brandes, C. M., King, K. M., \&t Markon, K. E. (2019). Psychology's replication crisis and clinical psychological science. Annual Review of Clinical Psychology, 15, 579-604.

U.S. Energy Information Administration. (n.d.). Coal and coke. Retrieved March 27, 2020, from https://www.eia.gov/international/data/world/coal-and-coke/coaland-coke-production

Verhagen, J., \& Wagenmakers, E.-J. (2014). Bayesian tests to quantify the result of a replication attempt. Journal of Experimental Psychology: General, 143, 14571475.

Whitmarsh, L. (2009). Behavioural responses to climate change: Asymmetry of intentions and impacts. Journal of Environmental Psychology, 29, 13-23.

Williams, M., \& Bond, C. (2020). Inoculating the public against misinformation about climate change: A replication study [Preprint]. PsyArXiv. https://doi.org/ 10.31234/osf.io/hqme7

Wynes, S., \& Nicholas, K. A. (2017). The climate mitigation gap: Education and government recommendations miss the most effective individual actions. Environmental Research Letters, 12, doi:10.1088/1748-9326/aa7541

Address correspondence to: Matt N. Williams School of Psychology Massey University Private Bag 102904 North Shore

Palmerston North 4442 New Zealand

E-mail: m.n.williams@massey.ac.nz

Received: January 20, 2020 Accepted: April 5, 2020 